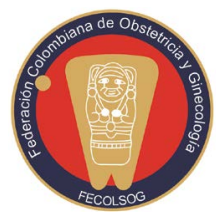

\title{
FECOLSOG: IMPROVING MATERNAL, SEXUAL AND REPRODUCTIVE HEALTH
}

nder the leadership of its Board of Directors, the Colombian Federation of Obstetrics and Gynaecology (FECOLSOG) has undertaken the task of developing a strategic plan looking to 2020. This new plan seeks to respond to the health situation in our country and it focuses on public health actions designed to improve maternal and perinatal indicators, develop interventions in sexual and reproductive health, work on training and recertification of our members, and update procedures that need to be covered by benefit plans paid through public funds.

Specifically, the objectives in the area of maternal and perinatal health are:

1. To reduce the percentage of deliveries by Cesarean section and of pre-term births.

2. To reduce maternal mortality.

In the area of sexual and reproductive health, the objectives are:

1. To enhance knowledge and empowerment to help women exercise their sexual and reproductive rights.

2. To continue working on the policies of the International Federation of Gynaecology and Obstetrics (FIGO) regarding the implementation of safe abortion.

3. To roll out training on methods for long-acting reversible contraceptives (LARC).

4. To reduce violence against women by means of a campaign focused on pregnant women based on our support to leading advocacy groups and organisations that fight violence against women.
On the other hand, training will be provided to specialists in obstetrics and gynaecology in areas such as early detection of abnormalities in order to avoid threatened pre-term labour, and hysteroscopy performed in the office, a procedure needed to be performed by the vast majority of gynaecologists in this country. Moreover, there will be a program consisting of simulation workshops in the following areas: instrumented delivery, management of obstetric emergencies and use of long-acting contraceptives, in the various regional offices. It is worth noting that the endoscopy committee will participate in the hysteroscopy training courses and that FECOLSOG has already purchased the various elements and supplies required for all the other activities.

Regarding changes in national health policies, the updated Healthcare Procedures Classification (CUPS) prompted a review of the list of procedures together with the specialists in each area, which resulted in the inclusion and modification of more than 140 items. We hope that this action will be of benefit for the patients, providing them with access to the interventions they may require.

The voluntary recertification programme will continue, with the endorsement of the Colombian Council of Accreditation and Recertification for Medical and other Similar Professions (CAMEC), for all the activities undertaken with our affiliated associations. This will result in benefits for all our members. Likewise, support for the various gynaecology trade associations in the country will continue.

We believe that partnerships with other scientific societies with which we share common goals are of benefit for our associates. Consequently, we will work on building networks or developing joint programmes for the furtherance of women's health in Colombia. 
Examples include the partnership created with the Colombian Society of Cardiology and Cardiovascular Surgery, aimed at working on a national policy for the prevention of cardiovascular diseases as one of the main causes of death among postmenopausal women.

With the leadership of our regional boards of directors, we expect our affiliates to be the driving force in all aspects of training for the medical community and for the patients in the areas described above. FECOLSOG will support all the initiatives put forward by our affiliates for achieving this end.

\section{Ivonne Díaz-Yamal, MD, FACOG} FECOLSOG President 